\title{
Structural and Electrical Investigation of New Melilite Compound $\mathrm{K}_{0.86} \mathrm{Na}_{1.14} \mathrm{CoP}_{2} \mathrm{O}_{7}$
}

\author{
Riadh Marzouki ${ }^{1,2, *}$, Youssef Ben Smida ${ }^{3}$, Abderrahmen Guesmi ${ }^{2}$, Samuel Georges ${ }^{4}$, \\ Ismat H. Ali ${ }^{1}$, Stefan Adams ${ }^{5}$, Mohamed Faouzi Zid ${ }^{2}$ \\ ${ }^{1}$ Chemistry Department, College of Science, King Khaled University, Abha 61413, Saudi Arabia. \\ ${ }^{2}$ Laboratory of Materials, Crystallochemistry and Applied Thermodynamics, Faculty of Sciences of \\ Tunis, University of Tunis El Manar, Tunisia. \\ ${ }^{3}$ National Center of Materials Sciences Research, Technopole Borj Cedria, 8027 Soliman, Tunisia. \\ ${ }^{4}$ CNRS, LEPMI, F-38000 Grenoble, France. \\ ${ }^{5}$ Department of Materials Science and Engineering, Faculty of Engineering, National University of \\ Singapore, Singapore. \\ *E-mail: riadh.marzouki@ hotmail.fr
}

doi: $10.20964 / 2018.12 .75$

Received: 11 September 2018 / Accepted: 2 October 2018 / Published: 5 November 2018

\begin{abstract}
A new sodium-potassium cobalt diphosphate, $\mathrm{K}_{0.86} \mathrm{Na}_{1.14} \mathrm{CoP}_{2} \mathrm{O}_{7}$, is synthesized by solid state reaction method and characterized by X-ray diffraction (XRD) and impedance spectroscopy. The resulting structural model is supports by bond-valence-sum analysis (BVS) and charge distribution validations (CHARDIT) tools. The mixed pyrophosphate crystallizes in the tetragonal system, space group $\mathrm{P} 42 / \mathrm{mnm}$ with $\mathrm{a}=7.808(3) \AA, \mathrm{c}=10.757(3) \AA$. The structure is described as a $2 \mathrm{D}$ anionic framework with alkali cations sandwiched between layers. As mechanical grinder, ball-milling was used in order to reduce average particle size of the prepared powder. The optimal sintering temperature of the ceramic is $560^{\circ} \mathrm{C}$, leading to a relative density of $83 \%$. Their microstructure is characterized by scanning electron microscopy (SEM). The conductivity measurements of the obtained ceramic are studied over a temperature range from $360^{\circ} \mathrm{C}$ to $480^{\circ} \mathrm{C}$. It shows that $\mathrm{K}_{0.86} \mathrm{Na}_{1.14} \mathrm{CoP}_{2} \mathrm{O}_{7}$ material is a low ionic conductor with a conductivity of $\sigma=8.26 \times 10^{-7}{\mathrm{~S} . \mathrm{cm}^{-1}}$ at $390^{\circ} \mathrm{C}$ and an activation energy of $1.34 \mathrm{eV}$. The bond valence site energy (BVSE) model is used to identify the conduction pathways for the monovalent cations, allowing a better correlation between the electrical and the structural data.
\end{abstract}

Keywords: Crystal structure; relative density; microstructure; impedance spectroscopy; conduction pathways.

\section{$\underline{\text { FULL TEXT }}$}


(C) 2018 The Authors. Published by ESG (www.electrochemsci.org). This article is an open access article distributed under the terms and conditions of the Creative Commons Attribution license (http://creativecommons.org/licenses/by/4.0/). 